\title{
A CONCEPTUAL MODELING OF SPATIO-TEMPORAL DATABASE TO ESTIMATE RUNOFF CHANGES IN URBANIZED WATERSHEDS
}

\author{
A. L. Schäfer \\ Federal University of Pampa, Bagé, Brazil -alexandro.schafer@ unipampa.edu.br
}

Technical Commission II

KEY WORDS: Modelling, Database, Spatial, Temporal, Hydrology, Monitoring, Change

\begin{abstract}
:
This paper presents the development of a conceptual model of a database that allows the monitoring of changes in watersheds over time and verifies the impact of these changes on runoff. The conceptual model was developed using ER modeling techniques. ER diagrams were constructed from the semantic analysis of the variables involved in the issue of runoff in watersheds using the Curve Number method of Natural Resource Conservation Service. The conceptual model was developed based on the concepts of states and events, and the use of time as a basis for organizing spatial data allowed to record the time and place of any changes. The model of representation of spatial data based on object was employed. Through the proposed conceptual model, it is possible to store the results of several simulations for a watershed, linking each simulation to a specific event and identifying which scenario is valid at the time. Thus, it is possible to identify quantitative changes related to runoff over time and relate them to the events that caused them and the entities involved in such events. The conceptual model supports the existence of alternate realities, allowing the simulation and comparison of past and future scenarios.
\end{abstract}

\section{INTRODUCTION}

The explosion of the population and rapid urban growth of recent decades have caused profound environmental and socioeconomic impacts. The changes in land use/land cover (LULC) related to human occupation, which vary spatially and occur at different levels of intensity over time, affect various components of the hydrological cycle, directly or indirectly.

To control or minimize the impacts on water resources generated by these processes, it is necessary to articulate their management with land management. This coordination must occur within a system of integrated management at watershed level, constituting a physical unit of management and economic and social development that extends beyond conventional political barriers.

In this context, one important concern is the development of ways to estimate the impact of changes that occur within a watershed in terms of runoff. Several computational tools developed in recent years make such estimates possible and since much of the data involved in this type of analysis have a spatial component, geographical information systems (GIS) are being increasingly used. Several studies have made use of GIS technology and hydrological models to assess the impacts of changes that occur in LULC in the hydrological response of a watershed (Bosch et al., 2003; Liu and Li, 2008; Miller et al., 2002; Ray et al., 2010; Wang et al., 2006).

Although widely used, GIS present some challenges when dealing with an important feature that is inherent in activities of planning and management for land use and water resources: the temporal dimension of the data. According to Martin et al. (2005), the exclusion of the temporal dimension in the data structure of GIS limits its interactivity with hydraulic or hydrological models, interfering with the user's ability to model the spatial variability of the studied area. In this sense, the inclusion of the dimension "time" in the structure of GIS is important. According to Couclelis (2005), the complexity of management, maintenance and operation of spatiotemporal data generates strong demand for research in this area, since several challenging issues remain unresolved.

Spatiotemporal databases (STDB) are being increasingly used in the development of information systems, in applications that require dealing with spatial and temporal data. STDB can provide a means to store, process, manage and analyze alphanumeric spatial, temporal, and spatiotemporal data, and make possible the recording of changes that occur over time. The integration of hydrological models to STDB enables estimates of runoff and analysis regarding its spatial distribution in a watershed. With this integration, it is possible to extract valid information related to a particular place in a particular scenario, check the changes that have occurred in the watershed between two scenarios and relate them to changes in runoff.

In order to enjoy the benefits of portability, expandability, easeof-maintenance and, most importantly, correctness, the design and development of an application should follow a complete methodology cycle (Brodie, 1982). In this sense, conceptual modelling is an important stage in planning the implementation of a successful database (Elmasri and Navathe, 2005). The conceptual modeling phase focuses on reflecting on the application requirements in a database design specified without the need for computer metaphors, which is understandable to the user, and that is complete, so that it can be translated into the logical phase that follows without any further user input (Tryfona and Jensen, 1999). In this context, this paper presents the development of a conceptual modeling of a database for monitoring changes in watersheds over time and verifying their impact on runoff. 


\section{CONTEXTUALIZATION OF THE PROBLEM OF ESTIMATING RUNOFF}

The conceptual modeling was developed using concepts of the Curve Number method from the Natural Resource Conservation Service (NRCS-CN method) (SCS, 1986) for estimate direct runoff depth.

The NRCS-CN method can be considered a combined loss model. All of the abstractions including interception, depression storage, evaporation, and infiltration are taken into account in the loss calculations of the NRCS-CN method (Karamouz et al., 2010). According to Chow et al. (1988), this method can be applied to determine the increase in the amount of runoff caused by urbanization in a watershed. Reduced to thumbnail basics, the method calculates an event direct runoff depth (R) arising from a rainfall of depth $(\mathrm{P})$ and a storage index $\mathrm{S}$ (also a depth), by the hyperbolic equation (Hawkins et al., 2009):

$$
\begin{gathered}
R=\frac{(P-0.2 S)^{2}}{(P+0.8 S)} \\
S=\frac{25400}{C N}-254
\end{gathered}
$$

in which, $\mathrm{CN}$ represents the runoff potential governed by hydrological soil property and LULC type.

In the NRCS-CN method, the watershed is discretized into homogeneous units, originated by the spatial overlap of the LULC and hydrological characteristics of soils. Hawkings et al. (2009) refer to these "parts" of the watershed as hydrological resource units (HRU). A value of $\mathrm{CN}$ is assigned for each HRU, according to the LULC and hydrological characteristics of the soil.

For a given event of precipitation, it is possible to calculate the runoff for each HRU (from equation 1) and, thus, verify the spatial distribution of direct runoff and the total volume of runoff (Q) produced in an area, from Equation 3:

$$
Q=\sum_{i=1}^{n} A_{i} \times R_{i}
$$

Where $A_{i}$ is the area of each HRU; $R_{i}$ is the runoff in this HRU; and $\mathrm{n}$ is the total number of HRUs.

The LULC is usually based on the classes specified in tables published by the NRCS, or classes defined in other studies. Typical values for percentage of imperviousness for the urbanized areas can be obtained from the literature. From the values of percentage of imperviousness for each urban class, the average of imperviousness for a certain area, can be obtained by equation 4 :

$$
\overline{P I}(\%)=\frac{\sum_{i=1}^{n} A_{i} \times P I_{l u l c}}{\sum_{i=1}^{n} A_{i}}
$$

Where, Ai is the area occupied by each class of LULC; PI lulc is the percentage of imperviousness assigned to each class of LULC; $\mathrm{n}$ is the total number of polygons related to LULC.

The soils are classified according to their hydrological characteristics into hydrological soil groups A, B, C or D. According to Ray et al. (2010), studies suggest that, in the event of urbanization, soils can be compacted and behave like soil group D. Thus, although soil types are not considered to change over time, changes may occur in the hydrological characteristics of a particular soil type at a given location. Another important issue is that the hydrological characteristics of a particular soil type in the United States, the original country of the NRCS-CN method may differ from the hydrological characteristics of the same soil in other countries. For the case of Brazil, Sartori (2010) proposes changes to the original hydrological classification of some soil types, arguing that future studies may lead to other changes in this classification.

To estimate the runoff for the NRCS-CN method, a current issue is the choice, by the user, of the coefficient of initial abstraction ( $\lambda$ ). According to Hawkins et al. (2009), the default value of 0.20 is somewhat vague and has been the subject of criticism. A recent report from NRCS recommends adopting a value of 0.05 .

In order to estimate the impact of changes in LULC in runoff at the level of sub-basin, county and/or zones of land use, it is important to be able to verify the conditions of LULC, the percentage of imperviousness and conditions of runoff for the watershed, as well as for certain sub-basins, counties or zones of land use.

The indices defined for zones of land use in the county master plan can be used as base values related to the percentage of imperviousness for scenario comparisons, generating a reference scenario for the condition of maximum imperviousness. From the weighted average of these values, it is possible to calculate a maximum imperviousness for each county, sub-basin or watershed, using equation 5 .

$$
\overline{P I}(\%)=\frac{\sum_{i=1}^{n} A_{i} \times\left(100-M R P_{z u}\right)}{\sum_{i=1}^{n} A_{i}}(5)
$$

Where $A_{i}$ is the area occupied by each zone; $M_{R P} P_{z u}$ is the minimum rate of permeability for each of the areas; $n$ is the total number of polygons of land use zones in the area of interest.

The direct runoff can be determined for each land use zone, from the application of the NRCS-CN method. Therefore, it is necessary to define values of $\mathrm{CN}$ for each zone. This definition can be made considering a composite $\mathrm{CN}$, from equation 6 .

$$
C N_{C}=C N_{P}+\left(\frac{100-M R P}{100}\right)\left(C N_{i m p}-C N_{P}\right)
$$

Where $\mathrm{CN}_{\mathrm{C}}$ is the curve number compound; $\mathrm{CN}_{\mathrm{P}}$ is the curve number of the permeable area (considered as being similar to hydrological conditions of good pasture conditions); MRP is the minimum rate of permeability; and CNimp is the curve number related to the impermeable area, considered to be equal to 98 .

In the consideration of spatiotemporal variations in the characteristics of the watershed and their impacts on runoff estimates, we start from the understanding that, for the same condition of precipitation, antecedent runoff condition (ARC) and $\lambda$, changes in the characteristics of the watershed can change its storage potential, leading to changes in the amounts related to direct runoff. In this study, we considered the following characteristics of the watershed: LULC, soil, the rate of urbanization and the percentage of imperviousness.

To assist in planning and land management, measurements and comparisons of the characteristics of the watershed and direct runoff can take place at the level of the watershed, sub-basin, county or land use zone.

In a space-time application, the change of state between one or more locations, entities, or both, is called an event. In this context, it can be assumed that for the same amount of 
accumulated rainfall, the amount of runoff generated in a watershed changes because of events, which, in turn, alters the state of the watershed.

From this background, the main premise that should be considered in the development of the STDB is that the characteristics of the watershed are changed due to events which, in turn, alter the state of one or more entities, modifying the conditions of runoff. Thus, it is valuable to be able to check the conditions of the characteristics of the watershed and direct runoff from the events for any of the states present for the entities over time, as well as to be able to relate the changes between two states to the events that led to the change.

In order to past and present situations, simultaneously considering alternative and future scenarios, the events considered in this paper include: a) changes in LULC; $b$ ) changes in the percentage of imperviousness related to certain classes of LULC; c) the occurrence of a survey in which a new complete scenario of the watershed is generated; d) the publication of studies that propose changes in the hydrological soil classification; f) changes in laws regarding land use zones (with respect to their geometry or the minimum rate of permeability), which changes the maximum allowable values for the percentage of imperviousness and direct runoff.

\section{CONCEPTUAL MODELING}

The conceptual modeling was developed based on the semantic analysis of the variables involved in verifying watershed characteristics and the estimated direct runoff, and also based on the requirements for a spatiotemporal application defined by Langran (1992), aiming to obtain responses to the questions raised in the phase of contextualization of the problem. Thus, we present in this section: a) the methodology used to estimate the impacts of changes in watershed characteristics on runoff; $b$ ) how the NRCS-CN method will be integrated into the STDB; c) the approach used for spatiotemporal modeling; and d) the E-R diagrams of conceptual modeling.

\subsection{The impact of changes in watershed characteristics on runoff}

For the development of the conceptual modeling, it is important to be clear not only with regards to the reality to be represented in computational means and requirements to be met, but also how the information system will work. As presented in the contextualization of the problem, the occurrence of an event leads to changes in watershed characteristics, which alters its potential for retention, changing the amounts of runoff produced for a given precipitation event. Figure 1 illustrates the process of verifying changes in watershed characteristics and estimating the impact of these changes on runoff between two scenarios, considering the same values of accumulated precipitation (Pac) and coefficient of initial abstraction $(\lambda)$ and the same antecedent Runoff Condition (ARC).

Verifying changes in watershed characteristics consists in the comparison between two scenarios with regards to a) the spatial distribution of LULC, hydrological soil group and imperviousness; b) the areas occupied by each class of LULC and hydrological soil group; and c) the average values of imperviousness for the areas of interest. From these comparisons it can be verified, for example, where the largest increases in urbanization and in imperviousness occurred.
Verifying changes in runoff also consists in the comparison between two scenarios, in this case with regards to: a) the $\mathrm{CN}$ average values in each area of interest, $b$ ) the spatial distribution of runoff, c) the volume of runoff produced in each area of interest; and d) the volume of runoff produced in places where there was an increase or decrease in direct runoff. From these comparisons it can be verified, for example, which county had the largest increase in runoff volume between two scenarios.

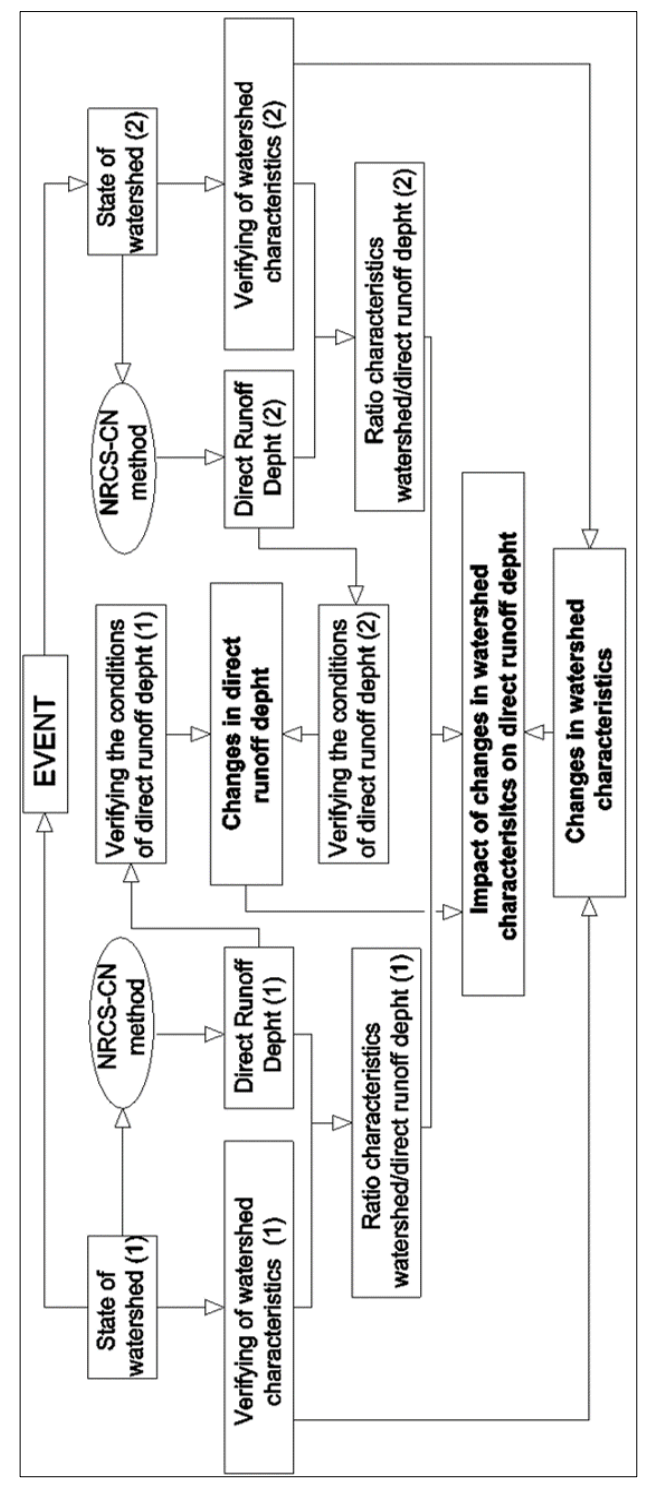

Figura 1: the fluxogram for verification of changes in watershed characteristics and impact on runoff.

The verification of the impact of changes in watershed characteristics on runoff is achieved by comparing the relationship 'characteristics of the watershed/runoff ' between two scenarios, in other words by considering the changes in watershed characteristics and the changes in the runoff. The relationship between changes in watershed characteristics and changes in the direct runoff allows the quantification of changes in watershed characteristics and their effects on the overall increase in runoff between the two scenarios. It is possible verify, for example, what the change in each class of LULC was and how much the increase in runoff volume was between two scenarios. 
Investigation of the relationship 'watershed characteristics/runoff' between the two scenarios allows a more detailed study. It is possible, for example, to verify the difference between the volumes of runoff generated in each class of LULC or hydrological soil group, between the two scenarios.

\subsection{Integration of STDB and NRCS-CN Method}

An important question for the development of conceptual modeling is how is make the integration between the STDB and the NRCS-CN method. According to Brimicombe (2010), there is a difference between modeling 'within GIS' and modeling 'with GIS'. In the first case, the modeling is done entirely within the GIS. In the second case, modeling is carried out outside of GIS, using specific software for modeling. In this work, modeling of direct runoff is carried out directly in GIS (in this case, the STDB) using the operators available in the database, through queries in SQL and Spatial SQL. This way, there was no exchange of data between GIS and another modeling software.

\subsection{Spatiotemporal data representation issues}

The spatiotemporal data models determine the manner and efficiency with which data can be accessed and manipulated in the information system (Le, 2005). In approaches that model the state of the real world as a scenario, it is simple to recover the state of a location at a given time, but hard to assess the changes that occurred between two dates. In approaches that model changes, it is easier to determine the changes that occurred between two dates than to determine the state of a place at a certain time. In approaches based on entity, the story of a single entity is easier to trace than the story of a particular place. In location-based approaches, it is simple to trace the history of a place. Combined or integrated approaches may be efficient for determining the history of a given location, entity and/or time (e.g., date).

Based on these considerations, we chose to adopt a combined approach for the development of the STDB, due to its greater flexibility regarding access to data, despite the fact that this type of approach is more complex and requires greater storage space, when compared to other approaches mentioned. To organize the changes that occur over time in watershed characteristics, we adopted an approach based on time. For the storage structure of spatiotemporal entities, we adopted the approach based on object. With respect to the time-based approach, rather than selecting a specific spatiotemporal data model, such as ESTDM (Peuquet and Duan, 1995), some general concepts from that approach were adopted. More specifically, we adopted the concept of location in time as the primary organizational basis for registering the changes. Thus, changes related to time were explicitly stored. The sequence of events over time, representing the spatial and temporal expression of some process was achieved via a timeline or time vector, i.e., a line along a single time dimension. The event usually represented a change in status (ie, change in some property, attribute, value) of an entity, a location or set of locations or entities (Peuquet and Duan, 1995). Thus, the timeline represents a progression of changes over time, starting from some initial date to another subsequent date.

The Spatio-Temporal Object Model (STOM) of Worboys (1994), was used to represent entities with spatiotemporal characteristics. This model was chosen taking into consideration the types of queries to be performed more frequently in the information system. Although it is necessary for the STDB to verify the changes in entities over time, modeling direct runoff requires complete scenarios of the watershed in study. Thus, we chose not to use approaches that store the changes that occur over time, mainly due to the complexity and time involved in the queries for determining a specific scenario, besides the possibility of inconsistencies and errors in the complete scenario, which would be reflected in the results of the verifications and simulations.

\subsection{Entity-Relationship Diagrams}

For presentation purposes, the E-R diagram originally developed was divided into three diagrams: a) Diagram of the watershed; $b$ ) Diagram of events; c) Diagram of verification and simulation. To facilitate the representation and comprehension of the diagrams, the attributes and some of the relationships were omitted.

\subsubsection{Watershed diagram}

The diagram of the watershed is shown in Figure 2. A watershed can be defined as the area of land drained by a major river and its tributaries. The watershed is represented by the entity Watershed. It is a discrete entity (identity and location is known) and has only a spatial domain: its boundaries and geometric properties do not change over time.

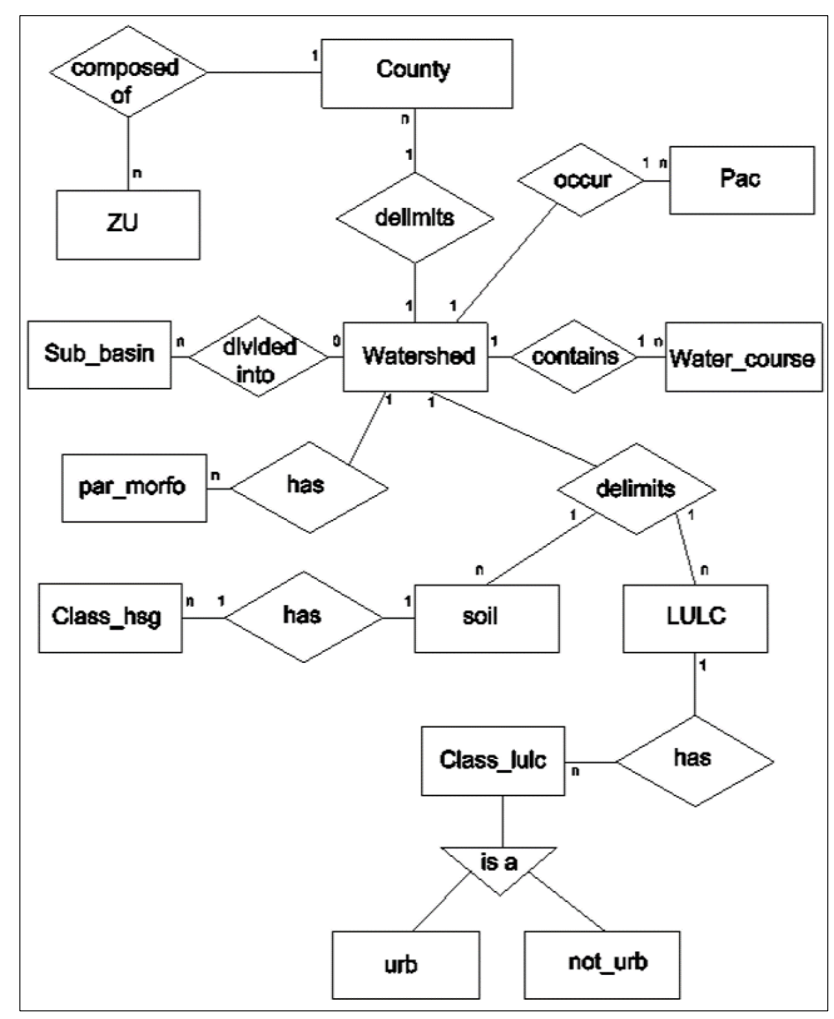

Figure 2: Diagram of watershed

The watershed contains the main river and its tributaries represented by the entity water_course. This is a discrete entity. It has spatial and temporal domains as its boundaries, geometric properties and attributes can change over time.

A watershed can be subdivided into sub-basins, which are the drainage areas of certain tributaries. The entity sub-basin is a discrete entity, represented by the object data model and has spatial and temporal domains, as its boundaries and geometric properties may change over time.

The land use/land cover is a continuous phenomenon, bounded by the watershed area and is represented by the entity $L U L C$. It 
can be spatially represented by the data field model. However, to be able to determine values related to runoff, it is necessary to determine the area covered by each type of LULC. Therefore, it is necessary that the units be discretized. For this reason, we chose to represent this entity by object data model. LULC has spatial and temporal domains, as its boundaries and geometric properties may change with time, as a result of the dynamics of occupation of the watershed. The entity class_lulc belongs to the LULC entity. This entity has the following attributes: type_LULC, which defines the type of LULC and imp, which stores the percentage of imperviousness of each LULC class. This entity is specialized into urbanized (urb) and not_urbanized (not_urb).

Soils are represented by entity soil. The distribution of soils in the watershed is a continuous phenomenon, bounded by the catchment area. Accordingly, for the $L U L C$, we chose to represent the soil entity by object data model. The soil entity has spatial and temporal domain, as its attributes may change over time as a result of the dynamics of occupation of the watershed or development of studies that verify the need for change in the hydrological soil classification. The entity class_hsg belongs to the soil entity. This entity has as attributes information about hydrological soil groups.

The counties are represented by the county entity. This entity has spatial and temporal domains. Its geometry and attributes may change over time. This entity is represented by the object data model and contains the entity $Z U$ (zone of use of the master plains). This entity is represented by the object data model, and has spatial and temporal domains. Its geometry and attributes may change over time.

The precipitation that occurs in the basin is represented by the entity Pac (accumulated precipitation). This entity has no spatial or temporal domain. It is represented by an attribute value. There may be multiple values of precipitation recorded for a given watershed. To facilitate the verification of the impacts of changes in the quantities of the runoff between two scenarios, a single value of precipitation is considered for the entire watershed. Each instance of Pac contains source information (whether it was obtained from monitoring stations, from precipitation maps or calculated using intensity-duration-frequency relationship).

Spatial heterogeneity in the watershed is represented in three hierarchical classes. The watershed (1), the sub-basin (2) and hydrological resource units (3). As hydrological resource units (HRUs) are obtained by the combination of LULC and soil, they are not stored in the database and therefore are not represented in the conceptual model. Where necessary, the HRUs are defined from an operation of spatial overlap between the LULC and soil, valid at the time or time interval specified by the user.

\subsubsection{Diagram of event}

The diagram of the event is shown in Figure 3. Changes in watershed characteristics and direct runoff can be determined by events related to the agents involved. The entity Event describes events that change the conditions of runoff in the watershed, or the parameters of the city master plan. The Event represents only temporal data (in this case, the date of occurrence), however this entity is not ordered temporally, allowing the registration of past, present and future events.

The events considered in this study are discrete, i.e., occurring only once and instantaneously, without duration or frequency. Although the changes in LULC may be gradual, they are not quantified constantly as they are obtained from surveys conducted at some time interval, and will be treated as sudden. An event can be related to only one or several changes, and can, thus, be related to various entities.

In addition to events occurring in the watershed, changes in entities of interest are also recorded. Thus, changes in the entities soil, LULC, County, Sub-basin or $Z U$ are represented by the entities chg_soil, Chg_LULC, Chg_SB and Chg_ZU, respectively. These entities present only the temporal domain, storing the date of occurrence and the cause of the change.

The entity $e v \_s o u r c e$ (event source) relates the event with the entities involved and contains a specific notation of the change that occurs. The entities related to events are: $L U L C$, soil, County and $Z U$.

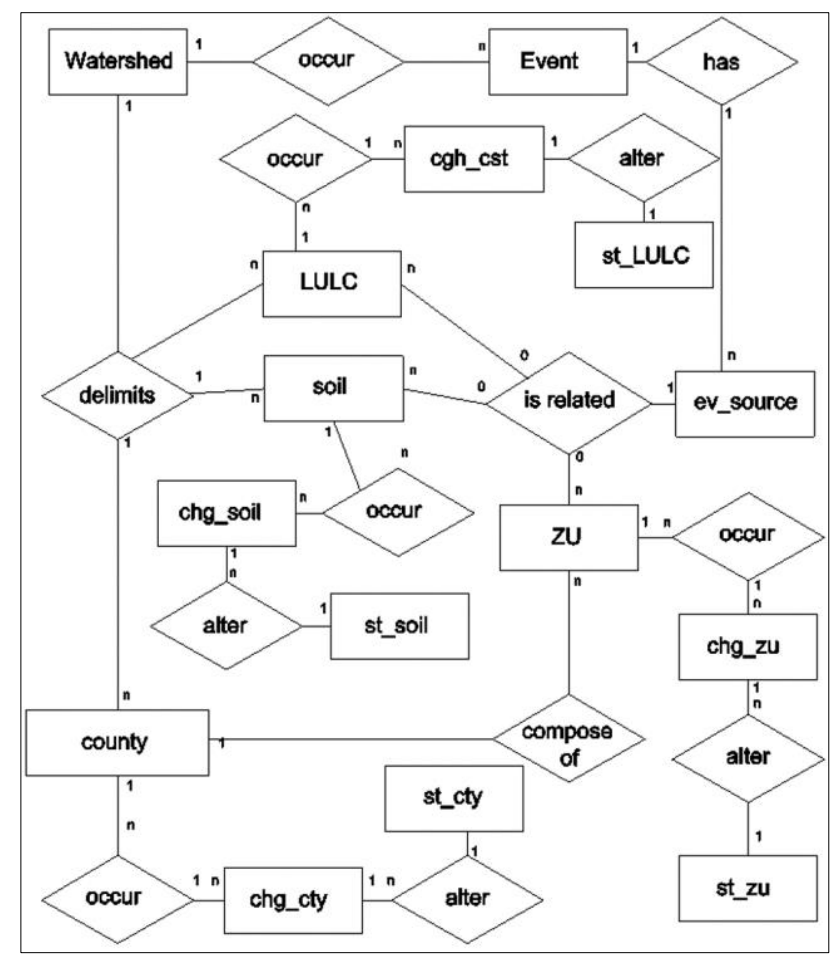

Figure 3: Diagram of event

The changes that occur in these entities alter their states over time. These changes are also recorded in STDB. The status of the entities Soil, LULC, County, Sub_basin and $Z U$ are represented by the entities $S t \_s o i l, S t \_L U L C, S t \_c o u n t y, S t \_s b a s i n$ and st_ZU, respectively. These entities present only a temporal domain, storing the start date and end date of validity of each state presented by the entity throughout its existence.

\subsubsection{Diagram of verification and simulation}

The diagram presenting the verification of changes in watershed characteristics and the simulation of direct runoff is shown in Figure 4 . To verify the values related to watershed characteristics and runoff for a given scenario, verifications and simulations performed are represented by the entity ver_sim (verification and simulation).

Verification and simulation can be performed based on the states of the entities that influence these values, or based on events that occur in the watershed and are responsible for altering the state of one or more of these entities. The entity ver_sim allows such 
a definition, in addition to setting the conditions of rainfall, Antecedent Runoff Condition, the coefficient of initial abstraction and the change of soil hydrological characteristics due to urbanization will be considered in one simulation or not. In addition, it stores the date when the verification and simulation was carried out.

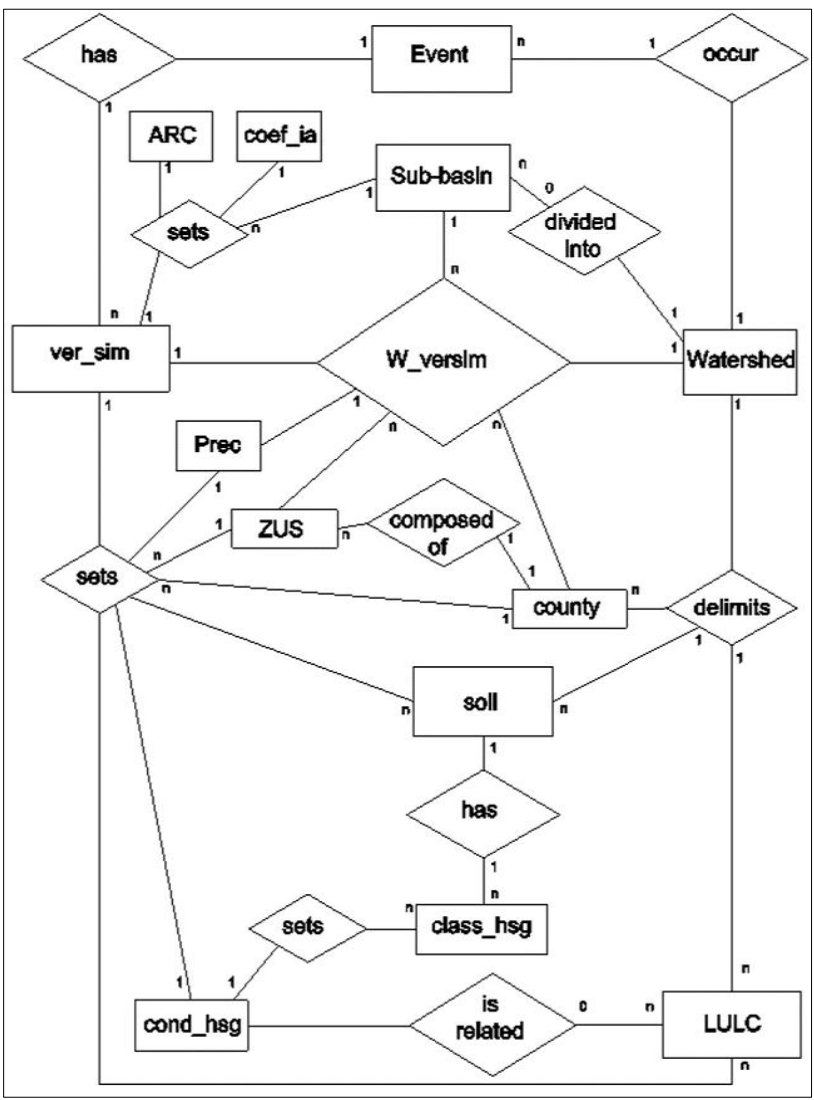

Figure 4: The diagram of verification of changes in watershed characteristics and simulation of direct runoff

\section{CONCLUSIONS AND FUTURE WORK}

This paper has presented the initial steps in developing a conceptual modeling of a STDB that will be used to estimate the impact of changes in watershed characteristics on runoff, employing the E-R conceptual model.

The E-R model allowed a simple and straightforward method for developing the conceptual modeling for estimating the impact caused by changes in watershed characteristics on the direct runoff. This is an important task, mainly in countries such as Brazil, in which hydric resource management, generally, is still not considered in the planning and management of land use. The conceptual modeling process led to several discussions about the entities, their attributes and relationships and about their spatial and temporal properties, requiring more knowledge of issues related to semantic and spatiotemporal data modeling in SIG.

As in the E-R conceptual model, the set of entities and relationships can be modeled only in two dimensions (attributes and instances) and, thus, it was not possible to represent the spatial and temporal properties, relationships and attributes of the entities. These properties needed to be described textually. Given the importance of conceptual modeling for life cycle of an information system, the conceptual model used for this modeling is of great relevance, providing a representation of the spatiotemporal properties of entities. As the E-R model does not allow this type of representation, the next step in the development of the STDB would be to search for conceptual models capable of performing this representation, such as the Geo-ER (Tryfona et al ., 2003), the UML-GeoFrame (Lisboa Filho, 2000; Lisboa Filho et al., 2007) and MADS (Parent et al., 1999).

\section{ACKNOWLEDGEMENTS}

This work was partially financed by the Foundation for Research Support of the Rio Grande do Sul - Fapergs.

\section{REFERENCES}

Bosch, D. J. et al., 2003. Hydrological and fiscal impacts of residential development: Virginia case study. Jounal of water resources planning and management, 129(2), pp. 107-114.

Brimicombe, A., 2010. GIS, environmental modeling and engineering. $2^{\mathrm{a}}$. ed. Taylor and Francis, Boca Raton.

Brodie, M. L., 1982. On the development of data models. In: On Conceptual Modeling, Brodie, M. L.; Mylopoulos, J. and Schmidt, W. J. (Eds.), Springer-Verlag, New York.

Chow, V.; Maidment, D.; Mays, L., 1988. Applied Hydrology. McGraw Hill, New York.

Couclelis, H., 2005. Space, time, geography. In: LONGLEY, P. A., et al. Geographical informations systems - Principles, Techniques, Management, and Applications. Sons, John Wiley \& Sons, New Jersey.

Elmasri, R.; Navathe, S. B., 2005. Sistemas de banco de dados. 4. ed. Pearson, São Paulo.

Hawkins, R. et al., 2009. Curve Number hydrology: state of the practice. ASCE, EUA.

Hawkins, R. et al., 2010. Continuing evolution of rainfall-runoff and the Curve Number precedent. Proceedings of $2^{\circ}$ Joint Federal Interagency Conference, Las Vegas.

Karamouz, M.; Moridi, A.; Nazif, S., 2010. Urban water engineering and management. CRC Press, EUA.

Le, Y., 2005. Representing time in base geographic data. Phd dissertation, Graduate Faculty of the University of Georgia. Atenas.

Lisboa Filho, J. 2000. Projeto Conceitual de Banco de Dados Geográficos através da Reutilização de Esquemas, utilizando Padrões de Análise e um Framework Conceitual. Porto Alegre: PPGC da UFRGS. Tese de Doutorado.

Lisboa Filho, J.; Sampaio, G. B.; Silva, E. O.; Gazola, A., 2007. Design and inplementarion of the valid time for spatio-temporal databases. In: International Conference on Enterprise Information Systems (ICEIS), Funchal, Madeira, Portugal, pp. 569-573.

Liu, X.; Li, J., 2008. Applications of SCS model in estimation of runoff from small watershed in Loess Plateau of China. Chinese geographic science, 18(3), pp. 235-241. 
Martin, P. et al., 2005. Interfacing GIS with water resource models: a state-of-the-art review. Journal of the American Water Resources Association, 41(6), pp. 1471-1487.

Miller, S. H. et al., 2002. Integrating landscape assessment and hydrologic modeling for land cover change analysis. Journal of the American Resources Association, 38(4), pp. 915-929.

Parent, C. Spaccapietra, S. and Zimányi, E., 1999. Spatiotemporal conceptual models: data structures + space + time. In: Proc. $9^{\text {th }}$ ACM GIS, Atlanta.

Peuquet, D. J.; Duan, N., 1995. An event-based spatiotemporal data model (ESTDM) for temporal analysis of geographical data. International journal of geographical information science, 9(1), pp. 7-24.

Ray, D. K.; Duckles, J. M.; Pijanowksi, B. C., 2010. The impact of future land use scenarios on runoff volumes in the Muskegon river watershed. Environmental Management, 46(3), pp. 351366.

Sartori, A., 2010. Desenvolvimento de critérios para classificação hidrológica de solos e determinação de valores de referência para o parâmetro $C N$. Tese de doutorado. Faculdade de Engenharia Civil, Arquitetura e Urbanismo. Universidade Estadual de Campinas. Campinas.

Tryfona, N.; Jensen, C. S., 1999. Conceptual data modelling for spatiotemporal applications. Geoinformatica, 3(3), pp. 245-268.

Tryfona, N.; Price, R.; Jensen, C. S., 2003. Spatiotemporal Conceptual Modelling. In: Spatiotemporal Databases: the Chorochronos approach, Koubarakis, M., Sellis, T., Frank, A.U., Grumbach, S., Güting, R.H., Jensen, C.S., Lorentzos, N., Manolopoulos, Y., Nardelli, E., Pernici, B., Schek, H.J., Scholl, M., Theodoulidis, B., Tryfona, N. (Eds.) SpringerVerlag, Germany.

United States Department of Agriculture - USDA, 1986. Urban hydrology for small watersheds. NRCS, EUA.

Wang, G. et al., 2006. Impact of land-use change on hydrological processes in the Maying River basin, China. Science in China Series D: Earth Sciences, 49, pp.1098-1110.

Worboys, M. F., 1994. A unfied model for spatial and temporal information. The computer journal, 37 (1), pp. 26-34. 